\title{
CONF-970834--7
}

\section{PRACTICAL FACTORS AFFECTING THE QUANTIFICATION OF ELEMENTAL CONCENTRATIONS IN BEAM-SENSITIVE CERAMICS BY EFTEM}

\author{
P. M. Rice and K. B. Alexander \\ Metals \& Ceramics Division, Oak Ridge National Laboratory, P.O. Box 2008, \\ Oak Ridge, TN 37831-6376
}

In order to obtain high spatial resolution microchemical data from beam-sensitive materials, alternative techniques which avoid the use of fine probes, such as energy-filtered imaging techniques must be used. Robust quantification procedures are currently under development. The quantification procedure which yields images whose intensities are proportional to the elemental concentrations (atoms per unit volume) has already been determined. ${ }^{1}$ The net core-loss intensity images, $\mathrm{S}_{\mathrm{i}}$, can be corrected for diffraction contrast by normalization with low loss images, whereas thickness variations are corrected by normalization with $t / \lambda$ maps. This procedure has been shown to give the correct value for the concentration ratio between two phases for a single elemental map. ${ }^{1}$ Determining concentration ratios between two elements in the same phase can actually be simpler, in theory, than the above procedure since it only requires dividing the net core-loss intensity images of two elements and correcting for the difference in cross-section $\left(\mathrm{C}_{\mathrm{x}} / \mathrm{C}_{\mathrm{y}}=\left[\mathrm{S}_{\mathrm{x}} / \mathrm{S}_{\mathrm{y}}\right]\left[\sigma_{\mathrm{y}} / \sigma_{\mathrm{x}}\right]\right)$. However, there are a few practical factors that must be considered in practice. First, the partial ionization cross-section $\sigma_{i}(\Delta, \beta, \alpha)$ is not only a function of the slit width, $\Delta$, and the collection half angle, $\beta$, but is also a function of the convergence angle $\alpha$. Fig. 1 shows the cross-sections for oxygen and nitrogen as a function of the convergence angle, as calculated by Gatan's EL/P software, for the experimental conditions typically used (i.e., $\mathrm{E}=300 \mathrm{kV}, \Delta=30 \mathrm{eV}, \beta=3.9 \mathrm{mrad}$ ). The plot also shows that the ratio of cross-sections for core-loss edges, as close in energy as oxygen and nitrogen are, is fairly independent of the convergence angle. Thus, to calculate elemental concentration ratios it is necessary to acquire the pre- and post-edge images for both (or all) core-loss edges of interest with a constant convergence angle and incident current density (i.e., keep the same illumination conditions). To avoid saturating the CCD for strong lower-loss edges, or collecting too little signal for weak higher-loss edges, it is necessary to vary the acquisition times for images of different elements. The resultant images (or profiles, see below) must then be normalized to constant acquisition time. In addition, directly ratioing two net core-loss intensity maps tends to result in noisy elemental concentration ratios particularly in regions in which the concentration of one (or both) of the elements is low.

For example, a low loss image, acquired with a $30 \mathrm{eV}$ slit, of an interface region between a glassy matrix and a $\mathrm{Si}_{3} \mathrm{~N}_{4}$ whisker on which a SiAlON phase had formed is shown in Fig. 2. The net coreloss intensity maps $\mathrm{S}_{\mathrm{i}}(\Delta, \beta, \alpha)$ for oxygen and nitrogen are displayed in Fig. $3 \mathrm{a}$ and $\mathrm{b}$ respectively. Fig. 4a shows the elemental concentration ratio map derived by dividing Fig. 3a by $3 \mathrm{~b}$ and correcting for the difference in cross-section and the discrepancy in acquisition times. The box in Figure 4a marks the region over which the profile across the interface, displayed in Figure $4 \mathrm{~b}$, was averaged. The oxygen-to-nitrogen ratio appears noisy in the glass phase because the nitrogen concentration is so low, and appears noisy in the $\mathrm{Si}_{3} \mathrm{~N}_{4}$ because the oxygen concentration is so low. [Note: running a median kernel filter on the net core-loss intensity maps before ratioing them would significantly improve the noise at the expense of spatial resolution.] Alternatively, carefully-aligned profiles (averaged over the 100 pixel boxes shown in Fig. 3) from the net core-loss intensity maps, can be divided, and corrected for the cross-section and any acquisition time differences, as shown in Figure 5. The averaged elemental concentration ratio profiles shown in Fig. 5 are quite smooth, resulting in much more consistent values for the concentration ratio within each phase while retaining the spatial resolution.

1. J. Bentley, E.L. Hall, E.A. Kenik, Proc. Ann MSA Meeting 53 (1995) 268.

This research was sponsored by the Division of Materials Sciences, U.S. Department of Energy, under contract DEAC05-96OR22464 with Lockheed Martin Energy Research Corp., and was conducted utilizing the SHaRE User Facilities at Oak Ridge National Laboratory.

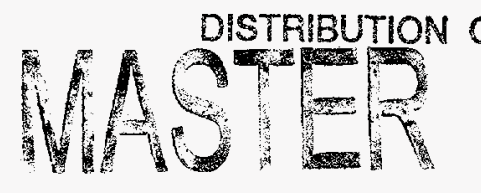

THIS DOCUMENT IS UNLIMITED 

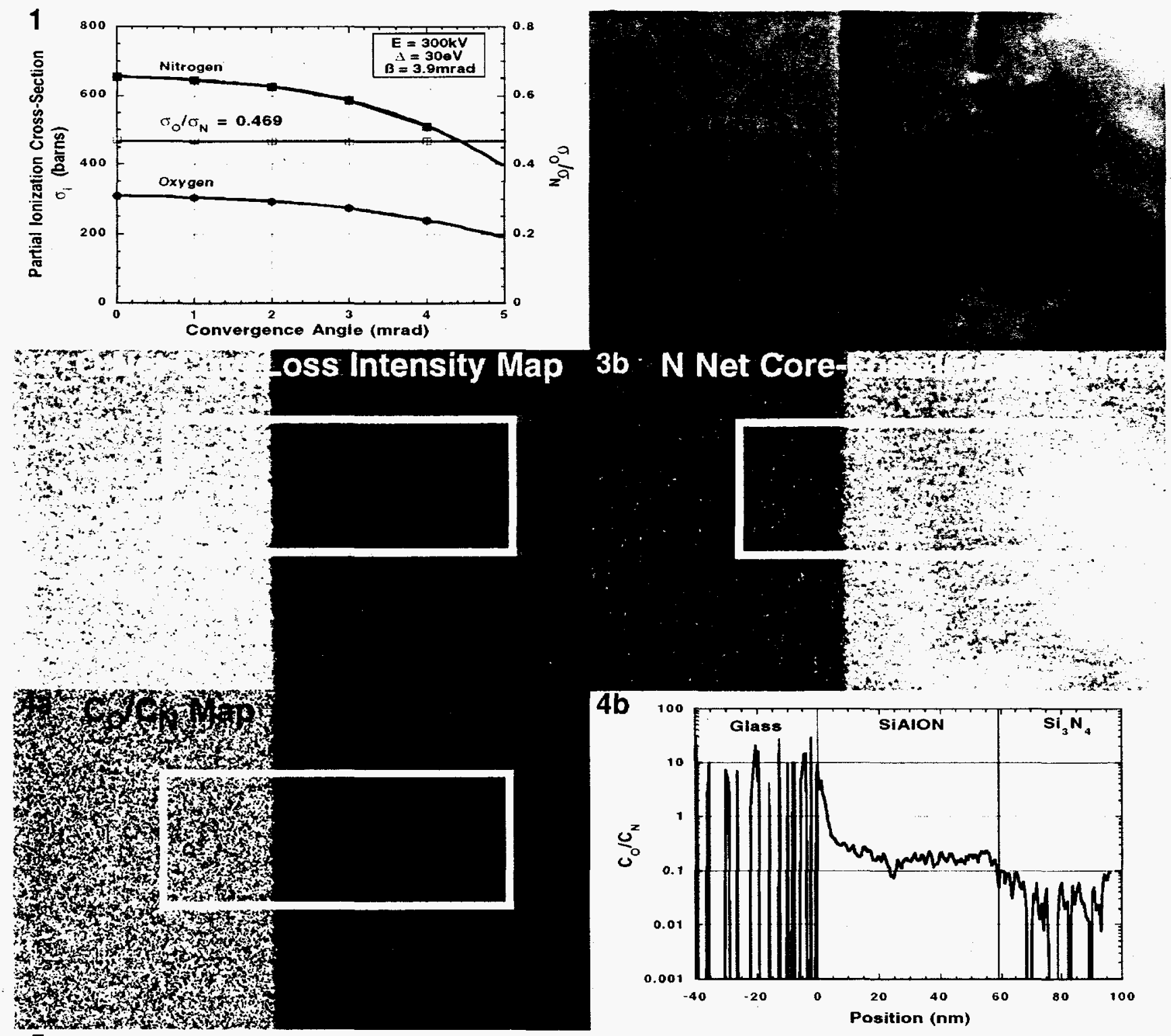

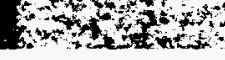
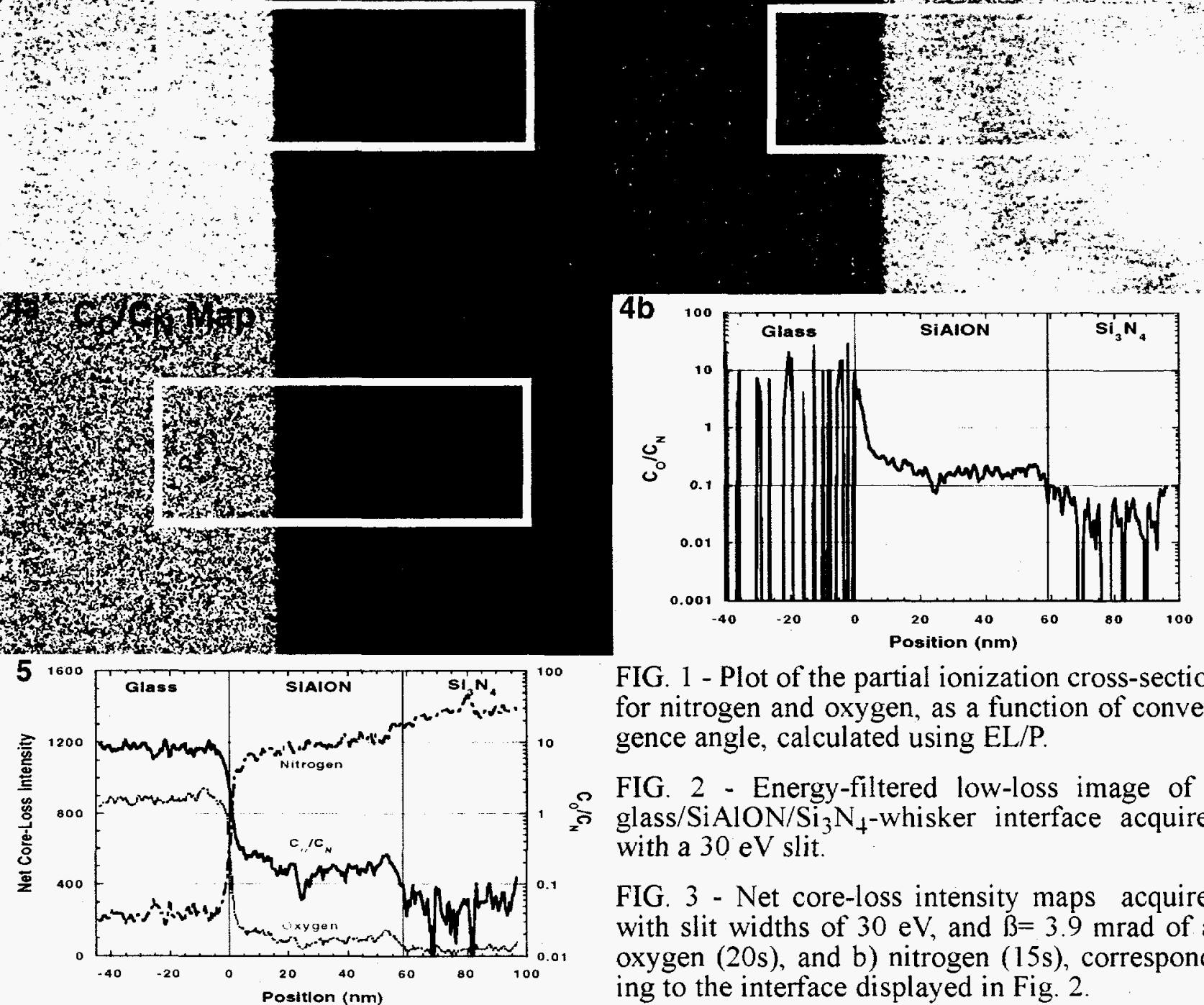

FIG. 1 - Plot of the partial ionization cross-section for nitrogen and oxygen, as a function of convergence angle, calculated using EL/P.

FIG. 2 - Energy-filtered low-loss image of a glass/SiAlON/Si ${ }_{3} \mathrm{~N}_{4}$-whisker interface acquired with a $30 \mathrm{eV}$ slit.

FIG. 3 - Net core-loss intensity maps acquired with slit widths of $30 \mathrm{eV}$, and $B=3.9 \mathrm{mrad}$ of a) oxygen $(20 \mathrm{~s})$, and b) nitrogen (15s), corresponding to the interface displayed in Fig. 2.

FIG. 4 - a) Elemental concentration ratio map calculated by dividing Fig. 3 a by $3 \mathrm{~b}$ and correcting for the differences in cross-section (see Fig. 1) and acquisition times. b) Concentration ratio profile $\mathrm{C}_{\mathrm{O}} / \mathrm{C}_{\mathrm{N}}$ across the interface calculated by averaging the intensities of 100 pixels (see box in Fig. 4a).

FIG. 5 - Plot displaying the averaged line profiles of the net intensities from the boxed regions of Fig. 3 . Note that the plot of the concentration ratio profile is less noisv than that shown in Fig. $4 \mathrm{~b}$. 


\section{DISCLAIMER}

This report was prepared as an account of work sponsored by an agency of the United States Government. Neither the United States Government nor any agency thereof, nor any of their employees, makes any warranty, express or implied, or assumes any legal liability or responsibility for the accuracy, completeness, or usefulness of any information, apparatus, product, or process disclosed, or represents that its use would not infringe privately owned rights. Reference herein to any specific commercial product, process, or service by trade name, trademark, manufacturer, or otherwise does not necessarily constitute or imply its endorsement, recommendation, or favoring by the United States Government or any agency thereof. The views and opinions of authors expressed herein do not necessarily state or reflect those of the United States Government or any agency thereof. 


\section{DISCLAMMER}

Portions of this document may be illegible in electronic image products. Images are produced from the best available original document. 